\begin{tabular}{|c|c|}
\hline Title & Redox-dependent axial ligand replacement and its functional significance in heme-bound iron regulatory proteins \\
\hline Author(s) & $\begin{array}{l}\text { Ogura, Mariko; Endo, Ryosuke; I shikawa, Haruto; Takeda, Y ukiko; U chida, T akeshi; I wai, Kazuhiro; Kobay ashi, } \\
\text { Kazuo; Ishimori, Koichiro }\end{array}$ \\
\hline Citation & $\begin{array}{l}\text { Journal of inorganic biochemistry, 182, 238-248 } \\
\text { https://doi.org/10.1016/.jinorgbio.2018.01.007 }\end{array}$ \\
\hline Issue Date & 201805 \\
\hline Doc URL & http:/hdl.handle.net/2115/77800 \\
\hline Rights & $\begin{array}{l}\text { (02018, El sevier. Licensed under the Creative Commons A ttribution-NonCommercial-NoDerivatives } 4.0 \text { International } \\
\text { http://rreativecommons.org/icenses/by-nc-nd/4.0/ }\end{array}$ \\
\hline Rights(URL) & http://creativecommons.org/icenses/by-nc-nd/4.0/ \\
\hline Type & article (author version) \\
\hline File Information & IRP_revised2_011218_4_lib.pdf \\
\hline
\end{tabular}

Instructions for use 


\section{Redox-dependent axial ligand replacement and its functional significance in heme-bound iron regulatory proteins}

Mariko Ogura $^{\mathrm{a}}$, Ryosuke Endo ${ }^{\mathrm{b}, \mathrm{c}}$, Haruto Ishikawa ${ }^{\mathrm{c}, 1}$, Yukiko Takeda ${ }^{\mathrm{d}}$, Takeshi Uchida, ${ }^{\mathrm{a}, \mathrm{b}}$, Kazuhiro Iwai ${ }^{\mathrm{d}}$, Kazuo Kobayashi ${ }^{\mathrm{e}}$ and Koichiro Ishimori ${ }^{\mathrm{a}, \mathrm{b}, ~ *}$

${ }^{\mathrm{a}}$ Graduate School of Chemical Sciences and Engineering, Hokkaido University, Sapporo 060-8628, Japan

${ }^{\mathrm{b}}$ Department of Chemistry, Faculty of Science, Hokkaido University, Sapporo 060-0810, Japan

${ }^{\mathrm{c}}$ Department of Molecular Engineering, Graduate School of Engineering, Kyoto University, Kyoto 615-8530, Japan,

${ }^{\mathrm{d}}$ Molecular and Cellular Physiology, Graduate School of Medicine, Kyoto University, Kyoto 606-8561, Japan

${ }^{\mathrm{e}}$ The Institute of Scientific and Industrial Research, Osaka University, Ibaraki, Osaka 567-0047, Japan

${ }^{1}$ Current address: Department of Chemistry, Graduate School of Science, Osaka University, Toyonaka 560-0043, Japan.

To whom correspondence should be addressed: Koichiro Ishimori, Phone: 81-11-706-2707.

E-mail: koichiro@sci.hokudai.ac.jp

Keywords: IRP; Ligand exchange; Oxidation; Resonance Raman; Pulse radiolysis 


\section{Abstract}

Iron regulatory proteins (IRPs), regulators of iron metabolism in mammalian cells, control the translation of proteins involved in iron uptake, storage and utilization by binding to specific iron-responsive element (IRE) sequences of mRNAs. Two homologs of IRPs (IRP1 and IRP2) have a typical heme regulatory motif (HRM), a consensus sequence found in "heme-regulated proteins”. However, specific heme binding to HRM has been reported only for IRP2, which is essential for oxidative modification and loss of binding to target mRNAs. In this paper, we confirmed that IRP1 also specifically binds two molar equivalents of heme, and found that the absorption and resonance Raman spectra of heme-bound IRP1 were quite similar to those of heme-bound IRP2. This shows that the heme environmental structures in IRP1 are close to those of proteins using heme as a regulatory molecule. Pulse radiolysis experiments, however, clearly revealed an axial ligand exchange from Cys to His immediately after the reduction of the heme iron to form a 5-coordinate His-ligated heme in heme-bound IRP2, whereas the 5-coordinate His-ligated heme was not observed after the reduction of heme-bound IRP1. Considering that the oxidative modification is only observed in heme-bound IRP2, but not IRP1, probably owing to the structural flexibility of IRP2, we propose that the transient 5-coordinate His-ligated heme is a prerequisite for oxidative modification of heme-bound IRP2, which functionally differentiates heme binding of IRP2 from that of IRP1. 


\section{Introduction}

Iron is an essential element for biochemical reactions in many organisms. It has the ability to readily accept and donate electrons, allowing it to function as an oxidant or reductant in a large number of biochemical reactions, including respiration, photosynthesis, and various types of metabolism. On the other hand, excess iron, particularly iron released from proteins or deposited iron in organs, is highly cytotoxic because it catalyzes the generation of free radicals that damage proteins, DNA and other cellular components. Therefore, iron metabolism is tightly regulated.

In mammalian cells, iron regulatory proteins (IRPs) are the primary regulators of iron metabolism, controlling the translation of proteins involved in iron uptake, storage and utilization by binding to specific iron-responsive element (IRE) sequences of mRNA [1]. IRPs have two homologs proteins, IRP1 and IRP2, both of which belong to the iron-sulfur cluster isomerase family and share significant homology [2]. Despite their high sequence homology, their mechanisms for iron sensing are distinctly different. In cells with abundant iron, a cubane type [4Fe-4S] cluster is formed in IRP1, which inhibits binding to IREs and converts IRP1 to a cytosolic aconitase, whereas the [4Fe-4S] cluster is disassembled in iron-depleted cells and apo-IRP1 acquires IRE-binding activity [3-6].

On the other hand, IRP2 is oxidized and ubiquitinated in iron-replete cells, leading to subsequent degradation by proteasomes, along with loss of its IRE binding activity [7-12]. For this degradation of the IRP2 protein, the oxidation of a domain specific to IRP2, the iron-dependent degradation (IDD) domain, which is not found in the sequence of IRP1 [13, 14], is essential. Lack of the IDD domain results in no degradation of the protein [10]. A previous study revealed that the oxidation of the IDD domain is triggered by heme binding to IRP2 and IDD domain-oxidized IRP2 is preferentially recognized by heme-oxidized IRP2 ubiquitin ligase-1 (HOIL-1) for ubiquitination [15]. 
Heme binding to the IDD domain in IRP2 and its functional significance has been examined by spectroscopy methods, including absorption, resonance Raman, and EPR spectra, and biochemical analysis of the oxidative modification [16]. The spectroscopic data clearly showed that the IDD domain specifically binds ferric heme via a cysteine residue $\left({ }^{201} \mathrm{Cys}\right)$ in the heme regulatory motif (HRM), a short consensus sequence for the heme binding site in heme-regulated proteins [17]. This binding triggers the oxidative modification of the IDD domain. Heme binding at the HRM cysteine residue is also thought to be the first step for the oxidative modification of a heme-dependent transcription factor important for bacterial heme biosynthesis, iron-responsive regulator (Irr), in a nitrogen fixing bacterium, Bradyhizobium joponicum $[18,19]$.

Although heme binding to Cys in the HRM is observed for various "heme-regulated" proteins [17, 20], heme-dependent oxidative modification has only been confirmed in IRP2 and Irr [14, 18, 19]. Heme-regulated proteins that use heme as a signaling or effector molecule, such as heme activator protein 1 (Hap1) [21], 5-aminolevulinate synthase (ALAS)-1 [22], ALAS2 [22], heme-regulated inhibitor (HRI) [23], and BTB and CNC homology 1 (Bach1) [24], can specifically bind heme, but no heme-induced protein oxidation has been reported. Based on a sequence alignment of heme-regulated proteins containing HRMs, we found that both IRP2 and Irr have His at the same position in the HRM (Cys-Pro-X-His), unlike other heme-regulated proteins, and positionally shifting of this His (Cys-Pro-X-X-His) in the HRM suppressed protein oxidation [16].

The crucial role of His in the HRM for protein oxidation was also supported by the fact that another homologous protein, IRP1, which has two HRMs lacking histidine residues, was not oxidized in the presence of heme under conditions where IRP2 is oxidized [15]. Although heme-induced oxidation was not observed for IRP1, incubation of IRP1 with heme prevented subsequent repression of ferritin synthesis in a wheat germ extract [25] and heme was found to be crosslinked to the specific region of IRP1 [26], suggesting that the IRE binding of IRP1 
is also regulated by the heme binding. As indicated in Fig. 1, the two HRM sequences in IRP1 are conserved in IRP2, which allowed us to speculate that IRP1 specifically binds heme at HRMs to regulate the IRE binding. A mouse expressing the IRP1 mutant with Cys in one of the HRMs displayed defects in iron regulation [27]. However, heme binding to these HRMs has not yet been examined.

In this paper, we found that IRP1 also specifically binds heme, and spectroscopically characterized the heme environments of both heme-bound IRP1 and IRP2. In particular, by using pulse radiolysis, we focused on the heme coordination structure of intermediates after reduction of the heme iron, revealing the structural factors differentiating heme binding to HRM in the IDD domain of IRP2 from those of other HRMs located outside of the IDD domain. 


\section{Experimental}

\subsection{Materials}

All chemicals were purchased from Wako Pure Chemical Industries (Osaka, Japan), Nacalai Tesque (Kyoto, Japan), or Sigma-Aldrich (St. Louis, MO, USA) and used without further purification.

\subsection{Protein expression and purification}

Procedures for the protein expression and purification were described by our previous paper [16]. High Five cells were cultured at $27{ }^{\circ} \mathrm{C}$ in Express Five serum-free medium (Invitrogen) supplemented with $16.5 \mathrm{mM}$ L-glutamine, $100 \mathrm{IU} / \mathrm{mL}$ penicillin $\mathrm{G}$ and 100 $\mu \mathrm{g} / \mathrm{mL}$ streptomycin, and infected with P3 baculovirus to express $\mathrm{His}_{6}$-tagged IRPs. At 60h after infection, the infected cells were harvested and centrifuged. The cells were washed and subsequently suspended in lysis buffer containing $50 \mathrm{mM}$ Tris- $\mathrm{HCl}(\mathrm{pH} 7.4), 10 \mathrm{mM}$ 2-mercaptoethanol, $0.2 \mathrm{mg} / \mathrm{mL}$ heat-treated ribonuclease A (Roche Diagnosis, Basel, Switzerland) and 1 tablet/50 mL protease inhibitor cocktail tablet (Complete EDTA-free, Roche Diagnosis). After incubation for $10 \mathrm{~min}$ on ice, the suspended cells were homogenized with a Dounce homogenizer (WATSON, Tokyo, Japan). The supernatant was applied to Ni-NTA agarose resin (QIAGEN, Hilden, Germany) pre-equilibrated with $50 \mathrm{mM}$ Tris-HCl (pH 7.4), and the mixture was incubated for $2 \mathrm{~h}$ at $4{ }^{\circ} \mathrm{C}$. After extensive washing, the bound protein was eluted with $50 \mathrm{mM}$ Tris- $\mathrm{HCl}$ (pH 7.4) buffer containing $300 \mathrm{mM}$ imidazole and 10 mM 2-mercaptoethanol.

For the purification of IRP1, the eluate was dialyzed against $50 \mathrm{mM}$ Tris- $\mathrm{HCl}(\mathrm{pH} 8.0)$ containing $10 \mathrm{mM}$ 2-mercaptoethanol to remove imidazole. The His ${ }_{6}$-tag was cleaved by TEV protease (Accelagen, San Diego, CA, USA) for $16 \mathrm{~h}$ at $4{ }^{\circ} \mathrm{C}$. After cleavage, the reaction mixture was again applied to Ni-NTA agarose pre-equilibrated with $50 \mathrm{mM}$ Tris-HCl (pH 7.4) 
containing $10 \mathrm{mM}$ 2-mercaptoethanol. The flow-through was concentrated and applied to a HiLoad 16/600 Superdex 200 pg gel-filtration column (GE Healthcare, Uppsala, Sweden) pre-equilibrated with $50 \mathrm{mM}$ Tris-HCl, $100 \mathrm{mM} \mathrm{NaCl}(\mathrm{pH}$ 7.4).

The purification procedure for IRP2 was essentially the same as that for IRP1. However, after the eluate was concentrated, buffer was exchanged to $50 \mathrm{mM}$ Tris-HCl, $0.5 \mathrm{mM}$ EDTA, and $1 \mathrm{mM}$ dithiothreitol (DTT) (pH 8.0) using a PD-10 MidiTrap column (GE Healthcare) instead of a HiLoad 16/600 Superdex 200 gel-filtration column to avoid partial aggregation during purification. The collected flow-through was exchanged with $50 \mathrm{mM}$ Tris-HCl, 100 $\mathrm{mM} \mathrm{NaCl}(\mathrm{pH}$ 7.4). The protein concentrations of IRP1 and IRP2 were estimated using the absorbance at $280 \mathrm{~nm}$ with extinction coefficients $\left(\varepsilon_{280}\right)$ calculated in ProtParam (http://web.expasy.org/protparam/) of 84,690 and 77,240 $\mathrm{M}^{-1} \mathrm{~cm}^{-1}$, respectively.

\subsection{Absorption spectroscopy}

All absorption spectra were obtained using a V-660 UV-Vis spectrophotometer (JASCO Corporation, Japan). Heme binding studies were conducted with difference absorption spectroscopy. Hemin was dissolved in $0.1 \mathrm{M} \mathrm{NaOH}$ and its concentration was determined based on the absorbance at $385 \mathrm{~nm}$ using an extinction coefficient $\left(\varepsilon_{385}\right)$ of $58.44 \mathrm{mM}^{-1} \mathrm{~cm}^{-1}$. Aliquots of a hemin solution $(500 \mu \mathrm{M})$ were added to both the sample cuvette containing 5 $\mu \mathrm{M}$ apo-IRPs, and the reference cuvette at $4{ }^{\circ} \mathrm{C}$. Spectra were recorded 2 min after the addition of hemin. The absorbance difference at $372 \mathrm{~nm}$ for IRP1 and $373 \mathrm{~nm}$ for IRP2 was plotted as a function of heme concentration. In the measurements of the absorption spectra, the addition of stoichiometric amounts of heme to IRPs resulted in an increase in free hemin, due to the low heme binding affinity of IRPs, and a broad absorption band from free hemin overlapped with the absorbance from heme-bound IRPs. We added one molar equivalent of heme to avoid appearance of the broad absorbance of free hemin in the Soret region. 


\subsection{Resonance Raman spectroscopy}

Resonance Raman spectra were recorded with a single monochromator (SPEX500M, Jobin Yvon, Edison, NJ, USA), equipped with a liquid nitrogen-cooled CCD detector (Spec-10:400B/LN, Roper Scientific, Princeton, NJ, USA). The spectra were obtained by excitation with $363.8 \mathrm{~nm}$ light from an argon ion laser (BeamLok 2065, Spectra Physics, Santa Clara, CA), 413.1 nm light from a krypton ion laser (BeamLok 2060, Spectra Physics), or $441.6 \mathrm{~nm}$ light from a helium-cadmium laser (KR1801C, Kimmon Electrics, Tokyo, Japan). The laser power at the sample point was adjusted to $\sim 5 \mathrm{~mW}$ for the ferric and ferrous forms and to $0.1 \mathrm{~mW}$ for the CO-bound form to avoid photodissociation. Raman shifts were calibrated with indene, $\mathrm{CCl}_{4}$, acetone, and an aqueous solution of ferrocyanide. The accuracy of the peak positions of well-defined Raman bands was $\pm 1 \mathrm{~cm}^{-1}$. Heme-reconstituted protein concentrations for Raman experiments were approximately $40 \mu \mathrm{M}$ in $50 \mathrm{mM}$ Tris- $\mathrm{HCl}(\mathrm{pH}$ 7.4), at room temperature. We added two molar equivalents of heme to IRPs for the measurements. In the resonance Raman spectra, a larger amount of heme was added to IRPs to improve the signal-to-noise ratio of the spectra, compared to that of the absorption spectra. However, non-specific scattering from free heme interferes with the detection of the Raman lines from the protein samples and less than the stoichiometric amounts of heme were added to IRPs for the measurements.

\subsection{Pulse radiolysis}

Pulse radiolysis experiments were performed with a pulse width of 8 ns and an energy of $27 \mathrm{MeV}$, using a linear accelerator at the Institute of Scientific and Industrial Research at Osaka University [28]. Samples for the pulse radiolysis measurements were solutions of heme-bound IRP1 or IRP2 in $50 \mathrm{mM}$ phosphate ( $\mathrm{pH}$ 7.4). The sample was placed in a quartz cell with an optical path length of $1 \mathrm{~cm}$, and the temperature of the sample was maintained at $25^{\circ} \mathrm{C}$. The light source for the monitoring light was a $150 \mathrm{~W}$ halogen lamp or a $200 \mathrm{~W}$ xenon 
lamp. After passing through the optical path, the transmitted light intensity was monitored using a fast spectrophotometric system composed of a Nikon monochromator and a Hamamatsu R-928 photomultiplier, and then analyzed using a Unisoku data analysis system. All data points at different wavelengths were obtained in separate measurements. 


\section{Results}

\subsection{Absorption spectra of heme-bound IRP1 and IRP2}

The absorption spectrum of IRP1 in the presence of ferric heme (solid line, Fig. 2A) exhibits a broad Soret peak at $372 \mathrm{~nm}$, with a shoulder at approximately $420 \mathrm{~nm}$. This was also found for IRP2 (solid line, Fig. 2B), where Cys in the HRM is ligated to the ferric heme iron [16], suggesting heme binding to Cys of the HRM in IRP1. To confirm specific heme binding to IRP1, spectrophotometric titration of heme to IRP1 was performed (inset, Fig. 2A). It is clear that two equivalents of heme bind to IRP1, which corresponds to the number of HRMs in IRP1 (Fig. 1), and supports the heme binding to Cys in the HRM. In IRP2, the spectrophotometric titration of heme to IRP2 (inset, Fig. 2B) indicates that three equivalents of heme can bind to IRP2, consistent with the presence of three HRMs in IRP2. One of the HRMs is located in the IRP2-specific domain, the IDD domain, and other two HRMs are conserved in both IRP homologs (Fig. 1). The close similarity of the absorption spectra between the two IRPs suggests that the heme environments for both IRP1 and IRP2 are quite similar, and characteristic of heme-regulated proteins [29]. Due to the addition of sub-stoichiometric amount of heme, the heme binding sites in IRPs were not fully occupied by heme. Based on the absorption intensities of the Soret peaks, the heme occupancies for IRPs are approximately $40 \%$, but the positions of the absorption peaks for heme-bound IRPs are insensitive to the amount of heme added to the solutions. The low heme occupancy in the heme binding sites of IRPs would not affect the spectroscopic characterization of heme-bound IRPs.

Upon reduction of the heme iron with sodium dithionite, the Soret band shifted to 423 and $425 \mathrm{~nm}$ for IRP1 and IRP2, respectively (Fig. 2A and B). Both peak positions can be categorized into the 6-coordinate ferrous low-spin heme such as observed for cytochrome $b_{5}$ [30] and the acidic form of cystathionine $\beta$-synthase (CBS) [31], where neutral Cys/His or 
His/His are ligated to the heme iron. In addition to the peak at approximately $425 \mathrm{~nm}$, however, both spectra showed a broad peak or shoulder at approximately $390 \mathrm{~nm}$, assignable to the Soret band of a neutral Cys-ligated heme [32], implying that the axial cysteine is protonated in a part of ferrous heme-bound IRPs. On the other hand, the absorption peaks in the Soret region of the carbon-monoxide (CO) adducts of heme-bound IRPs appeared at 421 nm (dotted lines, Fig. 2A and B), distinctly different from that of P450cam (450 nm) [33], but similar to that of myoglobin $(421 \mathrm{~nm})$ [34] or P420cam $(420 \mathrm{~nm})$ [35, 36]. The axial ligand for heme-bound IRP1-CO and IRP2-CO is, therefore, a neutral His or Cys, rather than an anionic Cys. As shown in Fig. 2, the absorption intensity of the Soret peak for the CO adduct of heme-bound IRP2 was substantially larger than that of CO-bound heme-IRP1. Although we have not yet identified the structural factors for the different absorption intensity between two proteins, the different heme environment of the HRM in the IDD domain from that outside of the IDD domain would result in the larger molar extinction coefficient of the CO adduct of heme-bound IRP2. Another possible factor is the different heme binding affinity of the CO adducts, and some amount of heme might be released from ferrous heme-bound IRP1 by the binding of CO. The absorption maxima for typical hemoproteins are summarized in Table 1.

\subsection{Resonance Raman spectra of ferric heme-bound IRP1 and IRP2.}

To further characterize the heme environmental structures of IRPs, we utilized resonance Raman spectroscopy. The resonance Raman spectra can provide valuable information about the heme coordination structure [37]. In the high-frequency region, the intense Raman band at approximately $1360-1370 \mathrm{~cm}^{-1}, v_{4}$, serves as an oxidation marker band. In the presence of heme, IRP1 and IRP2 displayed the $v_{4}$ band at $1372 \mathrm{~cm}^{-1}$, characteristic of ferric heme [37]. The spin-state marker band for the heme iron, $v_{3}$, was also detected in the high-frequency region, and both IRPs displayed two $v_{3}$ bands. In ferric heme-bound IRP1, the Raman band at $1489 \mathrm{~cm}^{-1}$ can be assigned to the 5-coordinate high-spin heme, and a shoulder band at 1500 
$\mathrm{cm}^{-1}$ is derived from the 6-coordinate low-spin heme (Ferric, Fig. 3A). The high-frequency region of the resonance Raman spectrum for ferric heme-bound IRP2 also has two $v_{3}$ bands at 1490 and $1500 \mathrm{~cm}^{-1}$. Thus, the heme coordination states in ferric heme-bound IRPs are a mixture of 5-coordinate high-spin and 6-coordinate low-spin hemes.

To spectroscopically examine the axial ligand for the heme iron in IRPs, we measured the low-frequency region of the resonance Raman spectra of ferric heme-bound IRPs excited at $363.8 \mathrm{~nm}$, in which the Fe-S stretching mode is expected to be detected in the region of 310 $350 \mathrm{~cm}^{-1}$ [38]. The resonance Raman spectra for ferric heme-bound IRP1 and IRP2 showed broad bands at approximately 331 and $333 \mathrm{~cm}^{-1}$, respectively (Fig. 4). To unambiguously assign the Fe-S stretching mode, we used ${ }^{54} \mathrm{Fe}$-substituted heme and the Raman bands were fitted by two Gaussian bands. The broad band consists of two bands at 331 and $345 \mathrm{~cm}^{-1}$, and only the band centered at $331 \mathrm{~cm}^{-1}$ for ferric ${ }^{56} \mathrm{Fe}$-heme-bound IRP1 displayed an ${ }^{54}$ Fe-isotopic shift to $333 \mathrm{~cm}^{-1}$ (Fig. 4A). In the resonance Raman spectrum of ferric ${ }^{56}$ Fe-heme-bound IRP2, the band centered at $333 \mathrm{~cm}^{-1}$ was also shifted to $335 \mathrm{~cm}^{-1}$ after substitution with ${ }^{54} \mathrm{Fe}$-heme (Fig. 4B). These isotopic shifts $\left(2 \mathrm{~cm}^{-1}\right)$ were also reported for Irr [39], where Cys in the HRM is ligated to the heme iron, and correspond to the calculated value $\left(2.2 \mathrm{~cm}^{-1}\right)$ [38] that confirms the ligation of cysteine to the heme iron in ferric heme-bound IRPs.

As found for ferric heme-bound Irr, lower Fe-S stretching frequencies were observed for IRPs and their line-widths were broad $\left(\sim 30 \mathrm{~cm}^{-1}\right)$ when compared with those of the typical Cys-ligated hemoprotein, P450cam (Fe-S frequency: $351 \mathrm{~cm}^{-1}$, line width: $\sim 15 \mathrm{~cm}^{-1}$ ) [38]. These spectral features are also encountered for heme-bound Irr that uses the cysteine residue in the HRM as the axial ligand for the heme iron [39]. The marker bands of the resonance Raman spectra for typical hemoproteins are summarized in Table 2.

\subsection{Resonance Raman spectra for ferrous heme-bound IRP1 and IRP2}


In the proposed mechanism for oxidative modification in IRP2 [16] and Irr [19], the reduced state of heme-bound forms binds molecular oxygen, which is one of the crucial steps for the generation of reactive oxygen species (ROS) in the oxidation of the protein moiety. To examine the environmental structures of reduced heme-bound IRPs, we measured the resonance Raman spectra for reduced heme-bound IRPs (Fig. 3). The $v_{4}$ band appeared at 1359 and $1360 \mathrm{~cm}^{-1}$ for IRP1 and IRP2, respectively. As found for ferric heme-bound IRPs, the reduced states of the heme-bound IRPs also gave two spin-state marker bands (1469 and $1492 \mathrm{~cm}^{-1}$ for IRP1; 1470 and $1492 \mathrm{~cm}^{-1}$ for IRP2), and reduced heme-bound IRPs had two spin states: the 5-coordinate high-spin and 6-coordinate low-spin states.

To get further insights into the heme environmental structures of reduced heme-bound IRPs, the resonance Raman spectra of the CO adducts were measured. In the high-frequency region, the C-O stretching mode of CO ligated to the heme iron is observed at 1920-1980 $\mathrm{cm}^{-1}$, while the Fe-C stretching mode is detected at 470-530 $\mathrm{cm}^{-1}$ [40]. As shown in Fig. 5A1, the Raman band at $494 \mathrm{~cm}^{-1}$, which was down-shifted to $484 \mathrm{~cm}^{-1}$, upon ${ }^{13} \mathrm{CO}$ substitution, were assigned to the $v(\mathrm{Fe}-\mathrm{CO})$ bands in the $\mathrm{CO}$ adduct of ferrous heme-bound IRP1. Meanwhile, in the high-frequency region (Fig. 5B1), one isotope-sensitive band appeared at $1962 \mathrm{~cm}^{-1}$ in the spectrum of the CO adduct of ferrous heme-bound IRP1 was assignable to the $v$ (FeC-O) band. In the $\mathrm{CO}$ adduct of heme-bound IRP2 (Fig. 5A2 and 5B2), the isotope-sensitive bands at 495 and $1961 \mathrm{~cm}^{-1}$ were assigned to $v(\mathrm{Fe}-\mathrm{CO})$ and $v(\mathrm{FeC}-\mathrm{O})$, respectively. Based on the inverse correlation of the frequencies between $v(\mathrm{Fe}-\mathrm{CO})$ and (FeC-O) (Fig. 6), the ligand trans to $\mathrm{CO}$ was proposed to be a neutral His, but not an anionic Cys. In addition to the $v(\mathrm{Fe}-\mathrm{CO})$ band from His-ligated heme, the isotope-sensitive Raman bands were observed at 525 and $526 \mathrm{~cm}^{-1}$ for the CO adducts of ferrous heme-bound IRP1 and IRP2, respectively (Fig. 5A1 and 5A2). These Raman bands can be assigned to $v$ (Fe-CO) of the 5-coordinate heme, suggesting the release of the axial ligand upon reduction. 
The ligation of His to the ferrous heme iron in heme-bound IRPs was further examined by the low-frequency regions of the resonance Raman spectra for heme-bound IRPs. As previously reported [41], the Fe-His stretching mode was observed at $200-250 \mathrm{~cm}^{-1}$ for the 5-coordinated ferrous heme. Because the 6-coordinate heme was dominant for ferrous heme-bound IRP1 and IRP2 (Fig. 2), we measured resonance Raman spectra of photo-dissociated CO adducts of ferrous heme-bound IRPs to detect the Fe-His stretching mode. In both IRP1 and IRP2, the characteristic Raman bands assignable to the Fe-His stretching mode were observed at 220 and $221 \mathrm{~cm}^{-1}$, respectively (Fig. 7), as found for deoxymyoglobin $\left(220 \mathrm{~cm}^{-1}\right)$ [41], supporting the idea that a neutral His is the axial ligand for the $\mathrm{CO}$ adducts of heme-bound IRPs.

The frequencies for the $\mathrm{Fe}-\mathrm{CO}$, and $\mathrm{FeC}-\mathrm{O}$ stretching modes also reflect the heme environment, particularly polarity in the exogenous ligand binding sites [42]. In the CO adduct of myoglobin, the $v(\mathrm{Fe}-\mathrm{CO})$ and $v(\mathrm{FeC}-\mathrm{O})$ bands were observed at 510 and $1944 \mathrm{~cm}^{-1}$, respectively $[43,44]$. Down-shifted $v(\mathrm{Fe}-\mathrm{CO})$ and up-shifted $v(\mathrm{FeC}-\mathrm{O})$ bands were also encountered for the "distal mutant" of myoglobin ( $v(\mathrm{Fe}-\mathrm{CO}): \sim 489 \mathrm{~cm}^{-1}, \quad$ (FeC-O): 1966 $\mathrm{cm}^{-1}$ ), where the distal histidine, ${ }^{64} \mathrm{His}$, was replaced with leucine or alanine $[45,46]$. The spectral similarity between the distal mutant of myoglobin and reduced heme-bound IRPs implies that the ligand-binding site of heme-bound IRPs is apolar.

\subsection{Axial ligand exchange evident by pulse radiolysis}

As shown in the absorption and resonance Raman spectra, the spectroscopic properties of ferric heme-bound IRPs were quite similar to that of ferric heme-bound Irr [39], a bacterial iron regulatory protein that uses heme as an effector molecule to regulate transcription activity, where Cys in the HRM is ligated to the heme iron. After reduction of the heme iron, however, the spectral features of heme-bound IRPs were significantly different from that of a typical anionic Cys-ligated hemoprotein such as P450cam, which were rather similar to those of the 
His-ligated hemoproteins including myoglobin and hemoglobin. Using mutations in the HRM region of the IDD domain in IRP2, Ishikawa et al. [16] have shown that the axial ligand for ferric heme-bound IRP2 is ${ }^{201}$ Cys in the HRM and one of the axial ligands for reduced heme-bound IRP2 is ${ }^{204} \mathrm{His}$, allowing them to propose a redox-dependent axial ligand exchange. Similar axial ligand replacement was also found for Irr [28]. In Irr, the axial ligand replacement of Cys in the HRM with His is induced immediately after the reduction of the heme iron to transiently form a 5-coordinate His-ligated heme, which is one of the intermediates for the oxidative modification and successive loss of the ability of Irr to bind to target DNA [28].

Formation of the 5-coordinate His-ligated intermediate in heme-bound IRPs was examined by the spectral changes after reduction of the heme using pulse radiolysis (Fig. 8). The kinetic difference spectrum for heme-bound IRP1 (Fig. 8A1) exhibited a broad positive absorption band in the region between 410 and $450 \mathrm{~nm}$, whereas in the kinetic difference spectrum at $100 \mu$ s for heme-bound IRP2 (Fig. 8B1), an absorption maximum at $435 \mathrm{~nm}$ was detected, indicating formation of 5-coordinate His-ligated heme, as found for heme-bound Irr [28]. The time course of the absorbance changes at $435 \mathrm{~nm}$ (Fig. 8B2) was fitted well to a single exponential curve, yielding a calculated rate constant of $2.3 \times 10^{4} \mathrm{~s}^{-1}$, but the constant absorbance was observed for the time range from 0.1 to $1.0 \mathrm{~ms}$ after the decay, indicating that the 5-coordinate His-ligated heme is a stable intermediate after the reduction of heme-bound IRP2. The absorption maximum at $435 \mathrm{~nm}$ remained $1.0 \mathrm{~ms}$ after the reduction as shown in Fig. 8B1 (dashed line), supporting the formation of the 5-coordinate His-ligated heme as the intermediate. On the other hand, the absorbance difference spectrum between ferric hemeand ferrous heme-bound IRP2 showed an absorption maximum at $425 \mathrm{~nm}$, not at $435 \mathrm{~nm}$ (solid line, Fig. 8B1), which corresponds to the Soret peak of ferrous heme-bound IRP2 (425 nm) (Fig. 2B). Because our previous mutational study reported that ferrous heme-bound IRP2 has a 6-coordinate His-ligated heme [16], the 6-coordinate His-ligated heme would, therefore, 
be formed more than $1.0 \mathrm{~ms}$ after the reduction of the heme.

On the other hand, the difference spectra at $100 \mu$ s and $1.0 \mathrm{~ms}$ after heme reduction showed no distinct absorption minimum at approximately $425 \mathrm{~nm}$, where the absorption peak for the 6-coordinate neutral Cys/His-ligated heme appears, suggesting that the 6-coordinate neutral Cys/His-ligated heme is insensitive to the reduction of the heme iron. However, considering that the 6-coordinate His/His-ligated ferrous heme exhibits a Soret band similar to that of the 6-coordinate neutral Cys/His-ligated ferric heme (Table 1) and that axial ligand replacement from Cys to His is induced for the 5-coordinate Cys-ligated heme, the axial cysteine residue for the 6-coordinate neutral Cys/His-ligated heme might be also replaced by His to form the 6-coordinate His/His-ligated heme after the reduction. Together with the results from the mutational study of IRP2 [16], immediately after the reduction, the axial cysteine residue, ${ }^{201} \mathrm{Cys}$, in the 5 -coordinate heme is dissociated from the heme iron, and the adjacent histidine, ${ }^{204} \mathrm{His}$, is then rapidly ligated to the ferrous heme iron to form the 5-coordinate His-ligated heme. In the 6-coordinate heme, we could not unambiguously determine the axial ligands immediately after the reduction of ferric heme-bound IRP2.

After more than $1.0 \mathrm{~ms}$, the 5-coordinate His-ligated heme is further converted into a 6-coordinate His-ligated heme as shown in the difference spectrum between dithionite-reduced and oxidized IRP2. The amino acid residue ligated to the heme iron more than $1.0 \mathrm{~ms}$ after the reduction has not yet been identified, but the IDD domain has only one histidine residue, ${ }^{204} \mathrm{His}$, and we speculate that a histidine residue from a region outside of the IDD domain coordinates to the heme iron, as suggested in our previous study [16].

In contrast to the difference spectrum for IRP2, the intermediate species with the absorption maximum at $435 \mathrm{~nm}$ was not observed for ferric heme-bound IRP1 (Fig. 8A1). The time course of the absorption change at $435 \mathrm{~nm}$ after the pulse radiolysis showed a rather slow decay with the rate constant of $3.3 \times 10^{3} \mathrm{~s}^{-1}$, compared to that of heme-bound IRP2 (2.3 $\times 10^{4} \mathrm{~s}^{-1}$ ). Although such slow absorbance changes after the pulse radiolysis might reflect the 
unstable baseline of the measurements, it is clear that the time course of the absorption changes in heme-bound IRP1 contained no fast phase observed for heme-bound IRP2. Instead of the absorption maximum at $435 \mathrm{~nm}$, a broad positive absorption band in the region between 410 and $450 \mathrm{~nm}$ appeared in the difference spectrum $100 \mu$ s after the reduction. It is likely that the absorption maximum at approximately $430-450 \mathrm{~nm}$ is derived from a 6-coordinate Cys/His-ligated heme, as found for pyridine-ligated P450cam (444 nm) [33]. In addition, another absorption maximum at approximately $410 \mathrm{~nm}$ was detected both $100 \mu$ s and $1.0 \mathrm{~ms}$ after the pulse radiolysis. The increased absorbance intensity at approximately $410 \mathrm{~nm}$ can be assigned to the formation of a ferrous 5-coordinate Cys-ligated heme, similar to ferrous P450cam (409 nm) [47]. The appearance of the absorption maxima at approximately 410 and $440 \mathrm{~nm}$ suggests that the axial ligand for heme-bound IRP1 immediately after the reduction is the cysteine residue, and reduction of the heme iron in ferric heme-bound IRP1 does not result in the rapid replacement of the axial cysteine, which is distinctly different from the case of ferric heme-bound IRP2.

Although IRP2 has two HRMs outside of the IDD domain, absorption maxima at approximately 410 and $440 \mathrm{~nm}$ were not detected. We cannot completely exclude the possibility that all of the heme binding sites in IRP2 form the transient 5-coordinate His-ligated heme after the reduction. As previously reported [16], the intensities of the absorption bands in the Soret and visible regions of the heme-bound IRP mutant lacking the IDD domain were more substantially decreased after gel filtration, compared to those of intact heme-bound IRP2, suggesting that the heme binding affinities of the HRMs outside of the IDD domain is lower than that of the HRM in the IDD domain. After gel filtration during sample preparation for the pulse radiolysis experiments, some amounts of heme might be released from the HRMs outside of the IDD domain. In addition, the absorption bands for the 5-coordinate and 6-coordinate Cys-ligated heme in the difference spectra were broad and rather featureless, which would make their detection in the difference spectra more difficult in 
the presence of the 5-coordinate His-ligated heme. The contribution of the heme binding spectral characteristics located outside of the IDD domain would be much less than those of the IDD domain to the difference spectra of heme-bound IRP2. 


\section{Discussion}

As we previously reported [39] and reviewed [29], "heme-regulated" proteins that use HRMs as their heme binding sites have some unique spectral characteristics. In IRP2, we have already examined the heme environmental structures of both of the ferric heme- and ferrous heme-bound forms, revealing that the heme environment is significantly different from that of the conventional Cys-ligated hemoprotein such as P450cam [16]. In this paper, we successfully identified the Raman band for the Fe-S stretching mode in the ferric heme-bound form, and this band was broad and down-shifted to approximately $330 \mathrm{~cm}^{-1}$, compared to those of a typical Cys-ligated hemoprotein, such as P450cam, and more closely resembles those of ferric heme-bound Irr [39]. The lower frequency for the Fe-S stretching mode has also been reported for nitric oxide synthase $\left(338 \mathrm{~cm}^{-1}\right)$, where the axial cysteine has only one hydrogen bond to stabilize ligation to the heme iron [48] (two hydrogen bonds are formed in P450cam [49]), and for heme-bound Bach1, which is also a HRM-containing heme-regulated protein using heme as the regulatory molecule [50]. The lower frequency of the Fe-S stretching mode in ferric heme-bound IRP2, therefore, means weak interactions between the axial ligand and surrounding amino acid residues and supports a role for heme as the signaling molecule for IRP2 [16]. Ferric heme-bound IRP1 also showed the lower frequency of the Fe-S stretching mode as observed for ferric heme-bound IRP2, suggesting that heme functions as the signaling molecule for IRP1 to derepress the ferritin synthesis [25].

Although spectral characteristics observed for heme-bound IRP2 were also found for heme-bound IRP1, the spectral changes after the reduction of the heme iron in heme-bound IRP1 were significantly different from those of IRP2 and Irr, as shown by our pulse radiolysis experiments (Fig. 8). The spectral changes immediately after the reduction of heme-bound IRP2 indicates formation of a 5-coordinate His-ligated ferrous heme, whereas 5-coordinate Cys-ligated and 6-coordinate Cys/His-ligated ferrous hemes were transiently formed in IRP1. 
Taking into account that the two HRMs outside of the IDD domain are conserved in both IRP1 and IRP2, the intermediate species with the 5-coordinate His-ligated ferrous heme is formed in the HRM of the IDD domain in IRP2, and hemes in the other HRM regions, outside of the IDD domain, are a mixture of 5-coordinate Cys-ligated and 6-coordinate Cys/His-ligated ferrous hemes. Together with the results from the present spectroscopic measurements, we can propose model structures of hemes in ferric heme- and ferrous heme-bound IRPs schematically represented in Fig. 9.

In the presence of heme, both IRP1 and IRP2 can specifically bind heme in their HRMs, and the coordination structures of these ferric heme-bound IRPs are a mixture of 5-coordinate Cys-ligated and 6-coordinate Cys/His-ligated hemes (Ferric State, Fig. 9). Although we have not yet identified the structural factors for the mixed heme coordination states, the Soret peak with a shoulder was observed in the presence of less than one equivalent of heme, indicating that these two conformers are in the equilibrium. Such conformational equilibrium was also encountered for some hemoproteins [51], where the ligand field of one of the heme ligands is rather weak. The lower frequencies of the Fe-S modes of ferric heme-bound IRPs would correspond to the weak ligand fields of the axial cysteines in heme-bound IRPs, compared to that of conventional Cys-ligated proteins such as P450, leading to the conformational equilibrium in heme-bound IRPs. In heme-bound IRP1, the ligated cysteines are ${ }^{118}$ Cys and ${ }^{300} \mathrm{Cys}$ in the HRMs, while in IRP2, three cysteine residues $\left({ }^{201} \mathrm{Cys}\right.$ in the HRM of the IDD domain, ${ }^{120} \mathrm{Cys}$, and ${ }^{375} \mathrm{Cys}$ in the HRMs outside of the IDD domain) are ligated to the heme iron. All of the heme environments including the heme-binding site in the IDD domain of IRP2 are quite similar and almost indistinguishable.

After the reduction of the heme ion (Reduction of Heme Iron, Fig. 9), the heme in IRP1 is reduced to maintain axial ligands to form the reduced 5-coordinate Cys-ligated and the 6-coordinate Cys/His-ligated hemes, as indicated by the absorption at approximately 410 and $440 \mathrm{~nm}$, respectively, in the difference spectra of the pulse radiolysis experiments (Fig. 8A1). 
These complexes are relatively stable, since they are detected at $1.0 \mathrm{~ms}$ after the reduction (dashed line, Fig. 8A1). After the transient formation of reduced Cys-ligated hemes, the axial cysteine would easily dissociate from the heme iron, due to the decreased relative affinity for ferrous heme iron compared to ferric heme. Once the axial cysteine is dissociated, a histidine residue will be coordinated to the ferrous heme iron to form the 5-coordinate His-ligated and 6-coordinate His/His-ligated heme (Ferrous State, Fig. 9). Due to the similar spectral pattern of the absorbance spectra between the His/His-ligated and Cys/His-ligated heme, we could not confirm the axial ligand replacement in the Cys/His-ligated heme and some amount of ferrous-heme bound IRP1 would maintain the Cys/His heme after reduction. The resonance Raman spectrum for reduced heme-bound IRP1 indicates two spin state markers arising from 5-coordinate high spin and 6-coordinate low spin hemes, but the absorption spectrum has no distinct absorption maximum at approximately $430 \mathrm{~nm}$, which is characteristic of a 5-coordinate His-ligated heme. Therefore, the 5-coordinate His-ligated heme population is rather small, compared to that of the 6-coordinate heme. Upon addition of CO (CO Adduct, Fig. 9), the CO adduct of the His-ligated heme is formed in heme-bound IRP1.

The coordination structures of hemes in the HRM outside of the IDD domain in IRP2 ("HRM outside of IDD domain" in Fig. 9) would be identical to that of IRP1. However, the appearance of the absorption maximum at $435 \mathrm{~nm}$ in the difference spectra of the pulse radiolysis experiments (Reduction of Heme Iron, Fig. 9) and our previous mutational study [16] clearly indicates that the reduction of the heme iron in the HRM of the IDD domain in IRP2 induces dissociation of ${ }^{201}$ Cys from the heme iron and ligation of the adjacent histidine, ${ }^{204} \mathrm{His}$, to form the 5 -coordinate His-ligated heme. In the 6-coordinate Cys/His-ligated heme in the HRM of the IDD domain, similar axial ligand replacement of ${ }^{201}$ Cys by ${ }^{204} \mathrm{His}$ might occur to form the 6-coordinate His/His-ligated heme, but we cannot exclude the possibility that protonated ${ }^{201} \mathrm{Cys}$ is ligated to the 6-coordinate heme after the reduction. 
Although ${ }^{204}$ His is located near ${ }^{201}$ Cys on the amino acid sequence, such ligand replacement requires a large structural change in the heme binding site. In CooA, one of the heme-containing transcription factors, the axial ligand of the ferric heme, ${ }^{75} \mathrm{Cys}$, is replaced by ${ }^{77}$ His upon the reduction of the heme iron [52], and the distance between the heme iron and sulfur atom of ${ }^{75}$ Cys is $4.8 \AA$ in ferrous CooA [53]. The x-ray structure of CooA indicates that only one hydrogen bond exists within $10 \AA$ from the heme iron in the proximal pocket, and a smaller number of the hydrogen bond in the heme binding site will reflect the flexibility of the polypeptide around heme binding site in CooA [52]. The rapid dissociation of ${ }^{201}$ Cys from the heme iron and ligation of ${ }^{204} \mathrm{His}$ in heme-bound IRP2 would, therefore, be due to the flexibility of the polypeptide in the IDD domain as suggested for CooA. The lower frequency of the Fe-S stretching mode in ferric heme-bound IRP2 also supports less number of the hydrogen bonds around the axial ligand. In addition, NMR measurements for the isolated IDD domain suggest that the structure of the IDD domain is disordered [54], and the heme binding site in the HRM of Bach2 is also disordered [55]. Such structural flexibility in the IDD domain would promote the axial ligand replacement from ${ }^{201} \mathrm{Cys}$ to ${ }^{204} \mathrm{His}$.

In the HRM of the IDD domain, more than $1.0 \mathrm{~ms}$ after the reduction, the 6-coordinate His/His-ligated or Cys/His-ligated heme is dominated by the ligation of the histidine residue from the region outside of the IDD domain (Ferrous State, Fig. 9). By addition of CO, replacement of one of the ligands, possibly ${ }^{204} \mathrm{His}$ [16] or protonated ${ }^{201} \mathrm{Cys}$, in the 6-coordinate heme and the ligation of $\mathrm{CO}$ to the 5-coordonate His-ligated heme are induced to form the $\mathrm{CO}$ adduct, in which the histidine serves as the trans ligand ( $\mathrm{CO}$ adduct, Fig. 9).

Our spectroscopic characterization of heme-bound IRPs immediately after reduction of the heme iron revealed that the 5-coordinate His-ligated heme is specifically formed in the HRM of the IDD domain in IRP2, although both ferrous heme-bound IRP1 and IRP2 showed the 6-coordinated His-ligated heme. Considering that IRP1 was not oxidized in the presence of heme under the conditions where IRP2 was oxidized [10], the 6-coordinate His-ligated 
heme after the reduction of the heme iron in IRPs would not effectively generate ROS to oxidize the protein moiety or the amino acid residues in the binding site of the 6-coordinate His-ligated heme would not be susceptible to oxidation by ROS. This allows us to speculate that molecular oxygen can bind to the 5-coordinate His-ligated heme and the amino acid residues constituting the oxygen binding site for the 5-coordinate His-ligated heme in the IDD domain of IRP2 are sensitive to the oxidation of ROS, leading to oxidative modification that is recognized by the ubiquitin ligase and results in proteasomal degradation. Such degradation of IRP2 is also promoted by binding F-box and leucine-rich repeat protein 5 (FBXL5) to IRP2 $[11,12]$. We have examined the correlation between two degradation mechanisms, but no evidence has been provided to link the heme-mediated degradation to the FBXL5-mediated degradation of IRP2.

In conclusion, we revealed the heme environmental structures of ferric heme- and ferrous heme-bound IRPs, including the intermediate species after reduction of the heme iron. Although ferric heme bound IRPs have the axial cysteine residues in the HRMs, the heme coordination structures were significantly different from those of typical Cys-ligated proteins such as P450. In the IDD domain of IRP2, ${ }^{201}$ Cys in the HRM is ligated to the ferric heme iron, while, upon reduction of the heme iron, ${ }^{201}$ Cys is dissociated and ${ }^{204}$ His will be ligated. Despite similar spectral characteristics in ferric heme- and ferrous heme-bound IRPs, the 5-coordinate His-ligated heme is specifically formed in the HRM of the IDD domain in IRP2, probably due to the structural flexibility of the IDD domain. The specific formation of this 5-coordinate His-ligated heme would be essential for oxidative modification of IRP2, which differentiates the functions of heme between these two IRPs. 


\section{Acknowledgements}

This work was supported by Grants-in-aid (23121501 and 15H00909, K. I.) from the Ministry of Education, Culture, Sports, Science, and Technology in Japan. 


\section{References}

[1] M.W. Hentze, M.U. Muckenthaler, N.C. Andrews, Cell, vol. 117, 2004, pp. 285-297.

[2] C. Fillebeen, K. Pantopoulos, Redox Rep., vol. 7, 2002, pp. 15-22.

[3] K. Pantopoulos, Hentze, M. W., Proc. Natl. Acad. Sci. USA, vol. 93, 1996, pp. 1267 - 1271.

[4] V. Gegout, Schlegl, J., Schlager, B., Hentze, M. W., Reinbolt, J., Ehresmann, B., Ehresmann, C., Romby, P., J. Biol. Chem., vol. 274, 1999, pp. 15052-15058.

[5] X. Brazzolotto, P. Timmins, Y. Dupont, J.-M. Moulis, J. Biol. Chem., vol. 277, 2002, pp. 11995-12000.

[6] W.E. Walden, A.I. Selezneva, J. Dupuy, A. Volbeda, J.C. Fontecilla-Camps, E.C. Theil, K. Volz, Science, vol. 314, 2006, pp. 1903-1908.

[7] P.A. DeRusso, C.C. Philpott, K. Iwai, H.S. Mostowski, R.D. Klausner, T.A. Rouault, J. Biol. Chem., vol. 270, 1995, pp. 15451-15454.

[8] B. Guo, J.D. Phillips, Y. Yu, E.A. Leibold, J. Biol. Chem., vol. 270, 1995, pp. 21645-21651.

[9] E.S. Hanson, L.M. Foot, E.A. Leibold, J. Biol. Chem., vol. 274, 1999, pp. 5047-5052.

[10] K. Iwai, Drake, S. K., Wehr, N. B., Weissman, A. M., LaVaute, T., Minato, K., Klausner, R. D., Levine, R. L., Rouault, T. A., Proc. Natl. Acad. Sci. USA, vol. 95, 1998, pp. 4924 - 4928.

[11] A.A. Salahudeen, J.W. Thompson, J.C. Ruiz, H.-W. Ma, L.N. Kinch, Q. Li, N.V. Grishin, R.K. Bruick, Science, vol. 326, 2009, pp. 722-726.

[12] A.A. Vashisht, K.B. Zumbrennen, X. Huang, D.N. Powers, A. Durazo, D. Sun, N. Bhaskaran, A. Persson, M. Uhlen, O. Sangfelt, C. Spruck, E.A. Leibold, J.A. Wohlschlegel, Science, vol. 326, 2009, pp. 718-721.

[13] J. Dupuy, A. Volbeda, P. Carpentier, C. Darnault, J.-M. Moulis, J.C. Fontecilla-Camps, Structure, vol. 14, 2006, pp. 129-139.

[14] K. Iwai, Klausner, R. D., Rouault, T. A., EMBO J., vol. 14, 1995, pp. 5350 - 5357.

[15] K. Yamanaka, H. Ishikawa, Y. Megumi, F. Tokunaga, M. Kanie, T.A. Rouault, I. Morishima, N. Minato, K. Ishimori, K. Iwai, Nature Cell Biol., vol. 5, 2003, pp. 336-340.

[16] H. Ishikawa, M. Kato, H. Hori, K. Ishimori, T. Kirisako, F. Tokunaga, K. Iwai, Mol. Cell, vol. 19, 2005, pp. 171-181.

[17] L. Zhang, L. Guarente, EMBO J., vol. 14, 1995, pp. 313 - 320.

[18] Z. Qi, I. Hamza, M.R. O'Brian, Proc. Nat. Acad. Sci. USA, vol. 96, 1999, pp. 13056-13061.

[19] C. Kitatsuji, K. Izumi, S. Nambu, M. Kurogochi, T. Uchida, S.-I. Nishimura, K. Iwai, M.R. O’Brian, M. Ikeda-Saito, K. Ishimori, Sci. Rep., vol. 6, 2016, pp. 18703.

[20] S.C. Tang, S. Koch, G.C. Papaefthymiou, S. Foner, R.B. Frankel, J.A. Ibers, R.H. Holm, J. Am. Chem. Soc., vol. 98, 1976, pp. 2414-2434.

[21] K. Pfeifer, K.S. Kim, S. Kogan, L. Guarente, Cell, vol. 56, 1989, pp. 291-301.

[22] J.T. Lathrop, Timko, M. P., Science, vol. 259, 1993, pp. 522-525.

[23] J. Chen, J. Pal, R. Petryshyn, I. Kuo, J. Yang, M. Throop, L. Gehrke, I. London, PNAS, vol. 88, 1991, pp. 315-319.

[24] K. Ogawa, J. Sun, S. Taketani, O. Nakajima, C. Nishitani, S. Sassa, N. Hayashi, M. Yamamoto, S. 
Shibahara, H. Fujita, K. Igarashi, EMBO J., vol. 20, 2001, pp. 2835-2843.

[25] J. Lin, S. Daniels-McQueen, M. Patino, L. Gaffield, W. Walden, R. Thach, Science, vol. 247, 1990, pp. 74-77.

[26] J. Lin, M. Patino, L. Gaffield, W. Walden, A. Smith, R. Thach, PNAS, vol. 88, 1991, pp. 6068-6071.

[27] D. Casarrubea, L. Viatte, T. Hallas, A. Vasanthakumar, R.S. Eisenstein, K. Schümann, M.W. Hentze, B. Galy, J. Mol. Med., vol. 91, 2013, pp. 871-881.

[28] K. Kobayashi, M. Nakagaki, H. Ishikawa, K. Iwai, M.R. O’Brian, K. Ishimori, Biochemistry, vol. 55, 2016, pp. 4047-4054.

[29] K. Ishimori, Y. Watanabe, Chem. Lett., vol. 43, 2014, pp. 1680-1689.

[30] S. Beck von Bodman, M.A. Schuler, D.R. Jollie, S.G. Sligar, Proc. Natl. Acad. Sci. USA, vol. 83, 1986, pp. 9443 - 9447.

[31] T. Omura, H. Sadano, T. Hasegawa, Y. Yoshida, S. Kominami, J. Biochem. , vol. 96, 1984, pp. 1491-1500.

[32] Y. Liu, Mo • ne-Loccoz, P., Hildebrand, D. P., Wilks, A., Loehr, T. M., Mauk, A. G., Ortiz de Montellano, P. R., Biochemistry, vol. 38, 1999, pp. 3733 - 3743.

[33] J. Dawson, L. Andersson, M. Sono, J. Biol. Chem., vol. 258, 1983, pp. 13637-13645.

[34] E. Antonini, M. Brunori, Hemoglobin and Myoglobin in Their Reactons with Ligands, North Holland, Amsterdam, 1971, pp. 193-199.

[35] S.A. Martinis, Blanke, S. R., Hager, L. P., Sliger, S. G., Rux, J. J., Dawson, J. H., Biochemistry, vol. 35, 1996, pp. 14530 - 14536.

[36] Y. Sun, W. Zeng, A. Benabbas, X. Ye, I. Denisov, S.G. Sligar, J. Du, J.H. Dawson, P.M. Champion, Biochemistry, vol. 52, 2013, pp. 5941-5951.

[37] T.G. Spiro, X.-Y. Li, in: T.G. Spiro (Ed.), Biological Applications of Raman Spectroscopy, vol. III, John Wiley \& Sons Inc., New York, 1988, pp. 1-37.

[38] P.M. Champion, B.R. Stallard, G.C. Wagner, I.C. Gunsalus, J. Am. Chem. Soc., vol. 104, 1982, pp. 5469-5472.

[39] H. Ishikawa, M. Nakagaki, A. Bamba, T. Uchida, H. Hori, M.R. O'Brian, K. Iwai, K. Ishimori, Biochemistry, vol. 50, 2011, pp. 1016-1022.

[40] N.-T. Yu, E.A. Kerr, in: T.G. Spiro (Ed.), Biological Applications of Raman Spectroscopy vol. III, John Wiley \& Sons, New York, 1988, pp. 39-95.

[41] T. Kitagawa, Nagai, K., Tsubaki, M., FEBS Lett., vol. 104, 1979, pp. 376 - 378.

[42] G.B. Ray, X.Y. Li, J.A. Ibers, J.L. Sessler, T.G. Spiro, J. Am. Chem. Soc., vol. 116, 1994, pp. 162-176.

[43] M. Tsubaki, R.B. Srivastava, N.T. Yu, Biochemistry, vol. 21, 1982, pp. 1132-1140.

[44] M.W. Makinen, Houtchens, R. A., Caughey, W. S., Proc. Natl. Acad. Sci. U. S. A., vol. 76, 1979, pp. 6042-6046.

[45] C.L. Anderton, R.E. Hester, J.N. Moore, Biochim. Biophys. Acta, vol. 1338, 1997, pp. 107-120.

[46] T. Li, M.L. Quillin, G.N.J. Phillips, J.S. Olson, Biochemistry, vol. 33, 1994, pp. 1433-1446.

[47] T. Egawa, T. Hishiki, Y. Ichikawa, Y. Kanamori, H. Shimada, S. Takahashi, T. Kitagawa, Y. Ishimura, J. Biol. Chem., vol. 279, 2004, pp. 32008-32017.

[48] J.P.M. Schelvis, V. Berka, G.T. Babcock, A.-l. Tsai, Biochemistry, vol. 41, 2002, pp. 5695-5701. 
[49] C.M. Krest, A. Silakov, J. Rittle, T.H. Yosca, E.L. Onderko, J.C. Calixto, M.T. Green, Nat. Chem., vol. 7, 2015, pp. 696-702.

[50] S. Hira, T. Tomita, T. Matsui, K. Igarashi, M. Ikeda-Saito, IUBMB Life, vol. 59, 2007, pp. 542-551.

[51] J. Igarashi, A. Sato, T. Kitagawa, T. Yoshimura, S. Yamauchi, I. Sagami, T. Shimizu, J. Biol. Chem., vol. 279, 2004, pp. 15752-15762.

[52] H. Nakajima, E. Nakagawa, K. Kobayashi, S.-i. Tagawa, S. Aono, J. Biol. Chem., vol. 276, 2001, pp. 37895-37899.

[53] W.N. Lanzilotta, Schuller, D. J., Thorsteinsson, M. V., Kerby, R. L., Roberts, G. P., Poulos, T. L., Nature Struct. Biol., vol. 7, 2000, pp. 876-880.

[54] C. Dycke, C. Bougault, J. Gaillard, J.-P. Andrieu, K. Pantopoulos, J.-M. Moulis, Biochem J, vol. 408, 2007, pp. 429-439.

[55] M. Watanabe-Matsui, T. Matsumoto, T. Matsui, M. Ikeda-Saito, A. Muto, K. Murayama, K. Igarashi, Arch. Biochem. Biophys., vol. 565, 2015, pp. 25-31.

[56] J. Igarashi, A. Sato, T. Kitagawa, I. Sagami, T. Shimizu, Biochim. Biophys. Acta, vol. 1650, 2003, pp. 99-104.

[57] D. Shelver, Kerby, R. L., He, Y., Roberts, G. P., Proc. Natl. Acad. Sci. U.S.A., vol. 94, 1997, pp. 11216 11220.

[58] J.H. Dawson, L.A. Andersson, M. Sono, J. Biol. Chem., vol. 257, 1982, pp. 3606-3617.

[59] Y. Yoshida, H. Kumaoka, R. Sato, J. Biochem., vol. 75, 1974, pp. 1211-1219.

[60] J. Yang, K. Ishimori, M.R. O'Brian, J. Biol. Chem., vol. 280, 2005, pp. 7671-7676.

[61] A.V. Wells, P. Li, P.M. Champion, S.A. Martinis, S.G. Sliger, Biochemistry, vol. 31, 1992, pp. 4384 - 4393.

[62] A. Feis, M.P. Marzocchi, M. Paoli, G. Smulevich, Biochemistry, vol. 33, 1994, pp. 4577-4583.

[63] T. Kitagawa, T. Sugiyama, T. Yamano, Biochemistry, vol. 21, 1982, pp. 1680-1686.

[64] S.D. Carson, I. Constantinidis, J. Mintorovitch, J.D. Satterlee, M.R. Ondrias, J. Biol. Chem., vol. 261, 1986, pp. 2246-2255. 


\section{FIGURES \& TABLES}

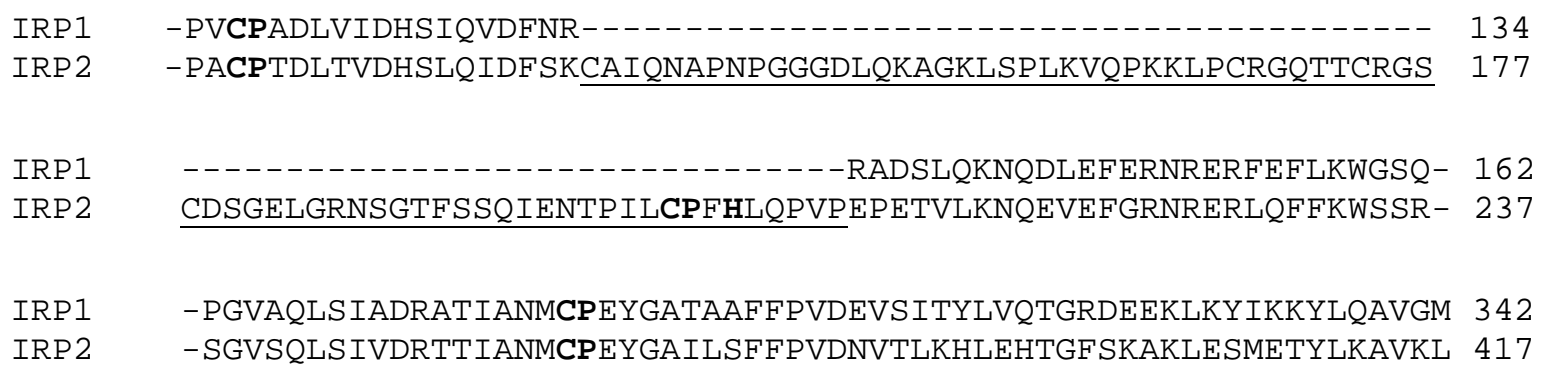

Fig. 1: Amino acid sequences including the HRM regions in IRP1 and IRP2. Cys, Pro, and His in the HRM regions are shown as bold letters. ${ }^{118}$ Cys $-{ }^{119}$ Pro and ${ }^{300} \mathrm{Cys}-{ }^{301}$ Pro in IRP1, and ${ }^{120}$ Cys- ${ }^{121}$ Pro, ${ }^{201}$ Cys- ${ }^{202}$ Pro-X- $-{ }^{204}$ His (IDD domain, underlined), and ${ }^{375} \mathrm{Cys}^{-376}$ Pro in IRP2. 

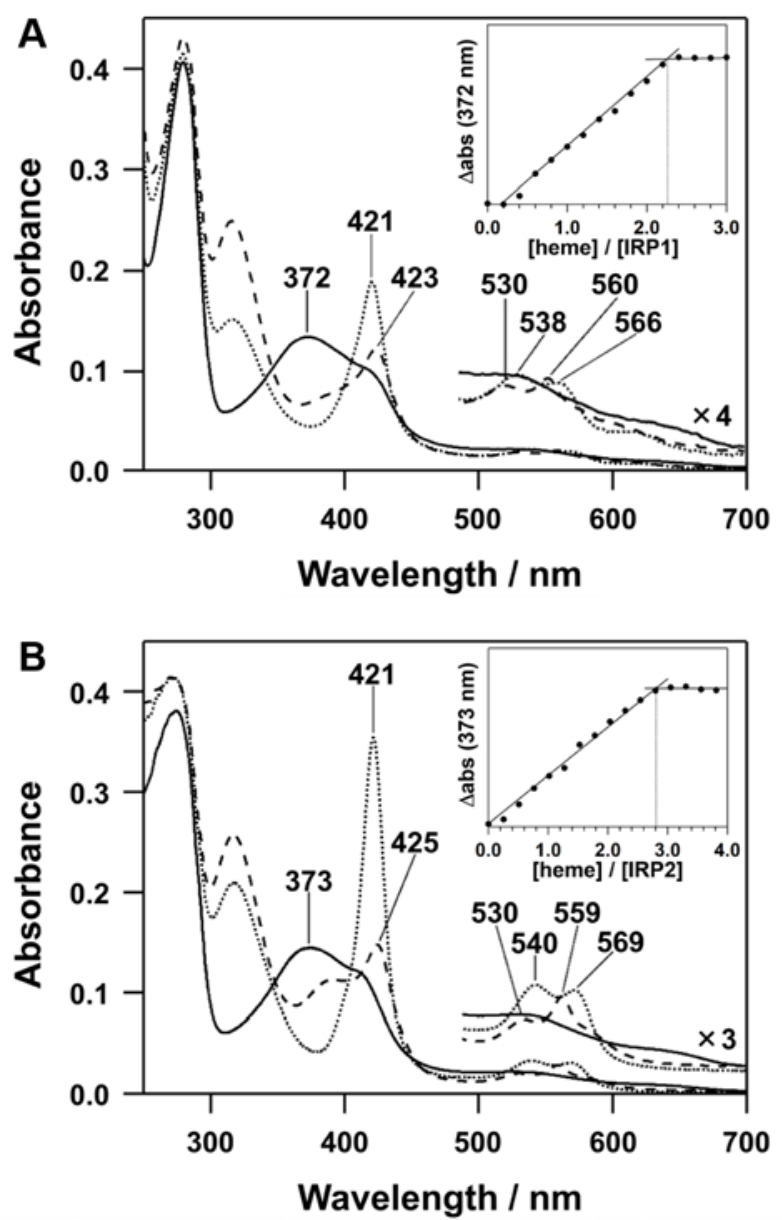

Fig. 2: Optical absorption spectra of heme-bound IRP1 (A) and IRP2 (B). The solid, dashed, and dotted lines represent the ferric heme-bound, ferrous heme-bound, and CO adducts of reduced heme-bound IRPs, respectively. (Inset) Heme titration of IRPs was followed by measurement of the absorbance at $372 \mathrm{~nm}$ and $373 \mathrm{~nm}$. The protein concentration was approximately $5 \mu \mathrm{M}$ in $50 \mathrm{mM}$ Tris- $\mathrm{HCl}$ buffer, $100 \mathrm{mM} \mathrm{NaCl}, \mathrm{pH}$ 7.4, in the presence of one molar equivalent of heme. 

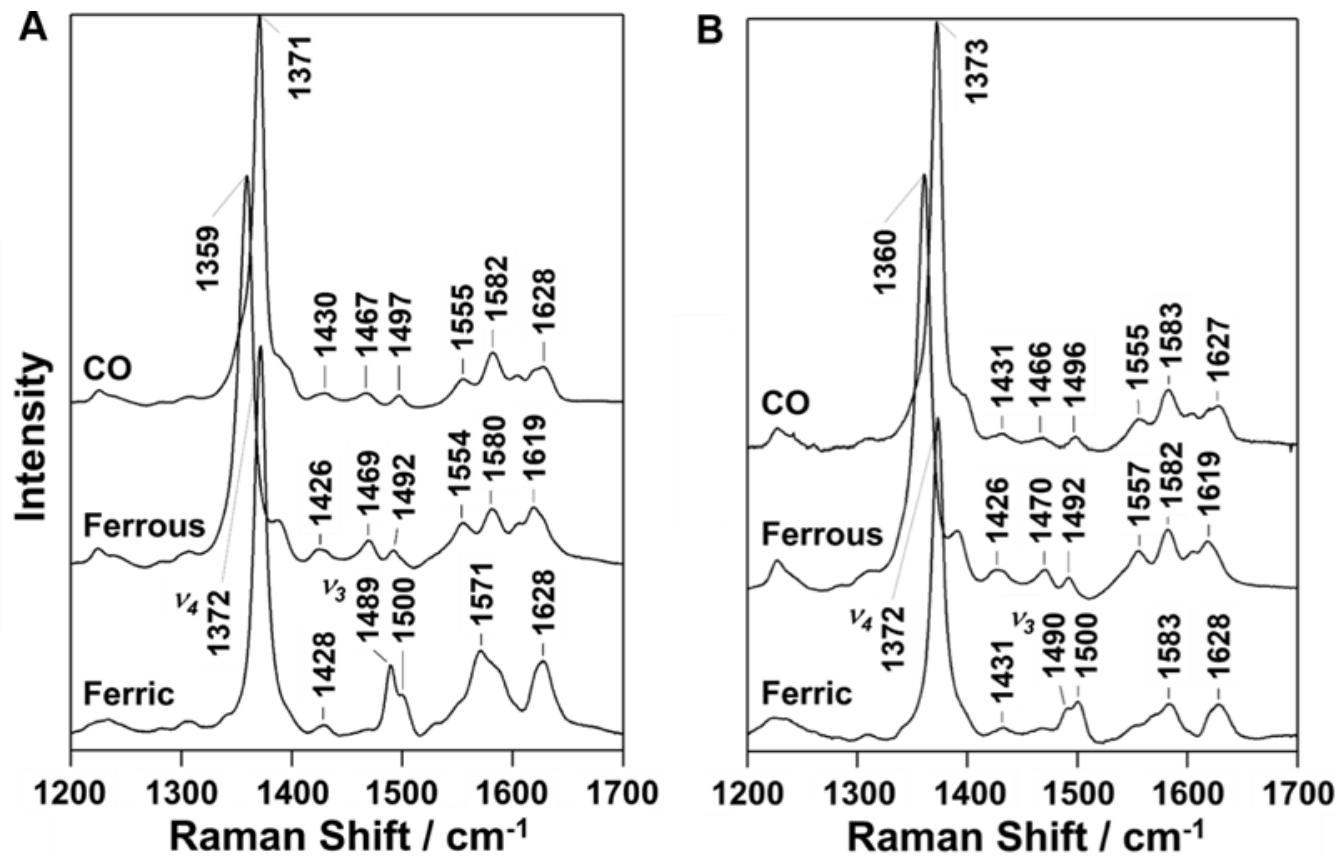

Fig. 3: Resonance Raman spectra of ferric heme-bound, ferrous heme-bound, and CO adducts of IRPs in the high frequency region. Resonance Raman spectra of IRP1 (A) and IRP2 (B) are shown. These spectra were obtained by excitation with $413.1 \mathrm{~nm}$. Samples were dissolved in $50 \mathrm{mM}$ Tris-HCl buffer, pH7.4. The protein concentration was approximately 40 $\mu \mathrm{M}$ in the presence of two molar equivalents of heme. 

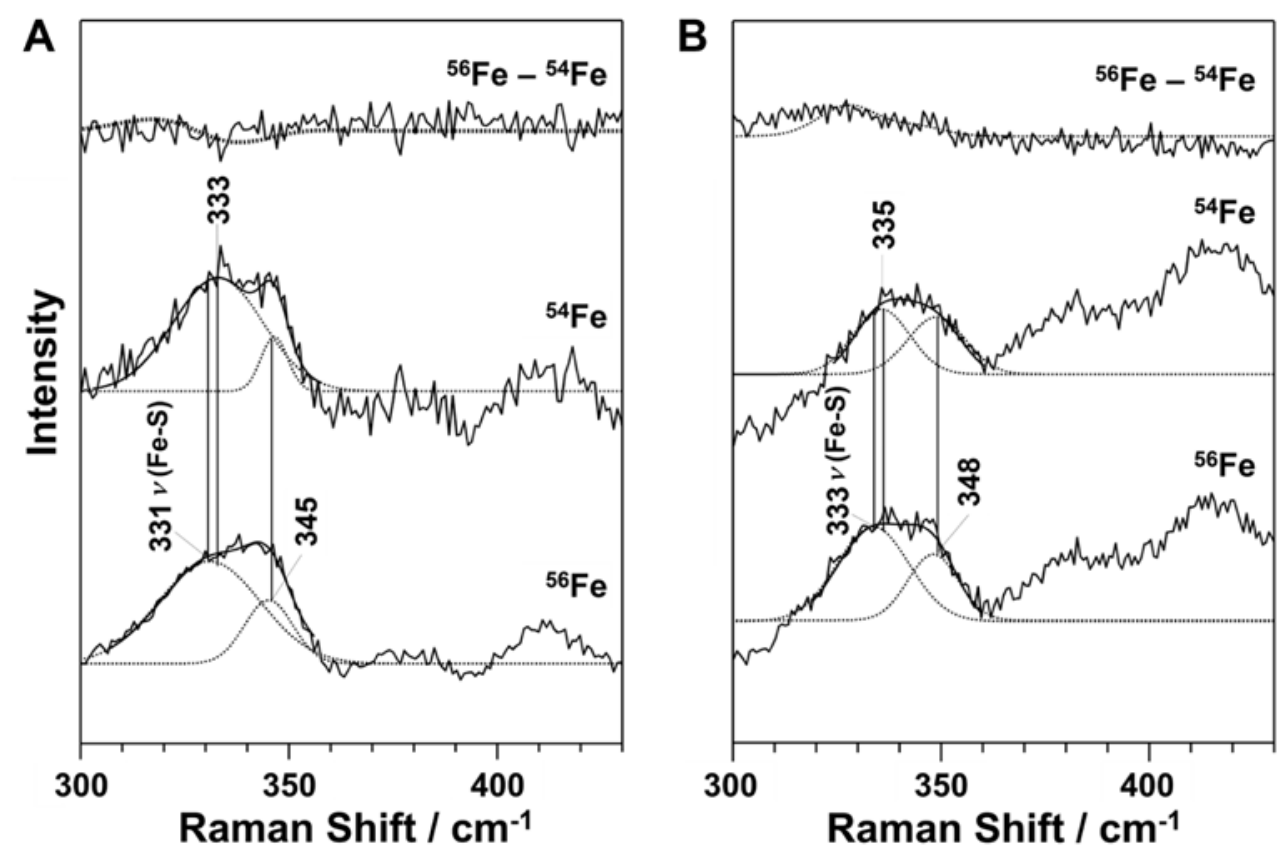

Fig. 4: Resonance Raman spectra of ferric heme-bound IRPs in the low frequency region. ${ }^{56} \mathrm{Fe}$ and ${ }^{54} \mathrm{Fe}$ heme-bound IRP1 (A), IRP2 (B). The spectra were obtained by excitation with $363.8 \mathrm{~nm}$ light from an argon ion laser. Samples were dissolved in $50 \mathrm{mM}$ Tris-HCl buffer, $\mathrm{pH}$ 7.4. The protein concentration was approximately $40 \mu \mathrm{M}$ in the presence of two molar equivalents of heme. The spectra show enlarged Raman lines at approximately $340 \mathrm{~cm}^{-1}$ for ${ }^{54} \mathrm{Fe}$ - and ${ }^{56} \mathrm{Fe}$-heme-bound IRPs and their difference spectra $\left({ }^{56} \mathrm{Fe}-{ }^{54} \mathrm{Fe}\right)$. The Raman lines were fitted by two Gaussian functions (dotted lines). 

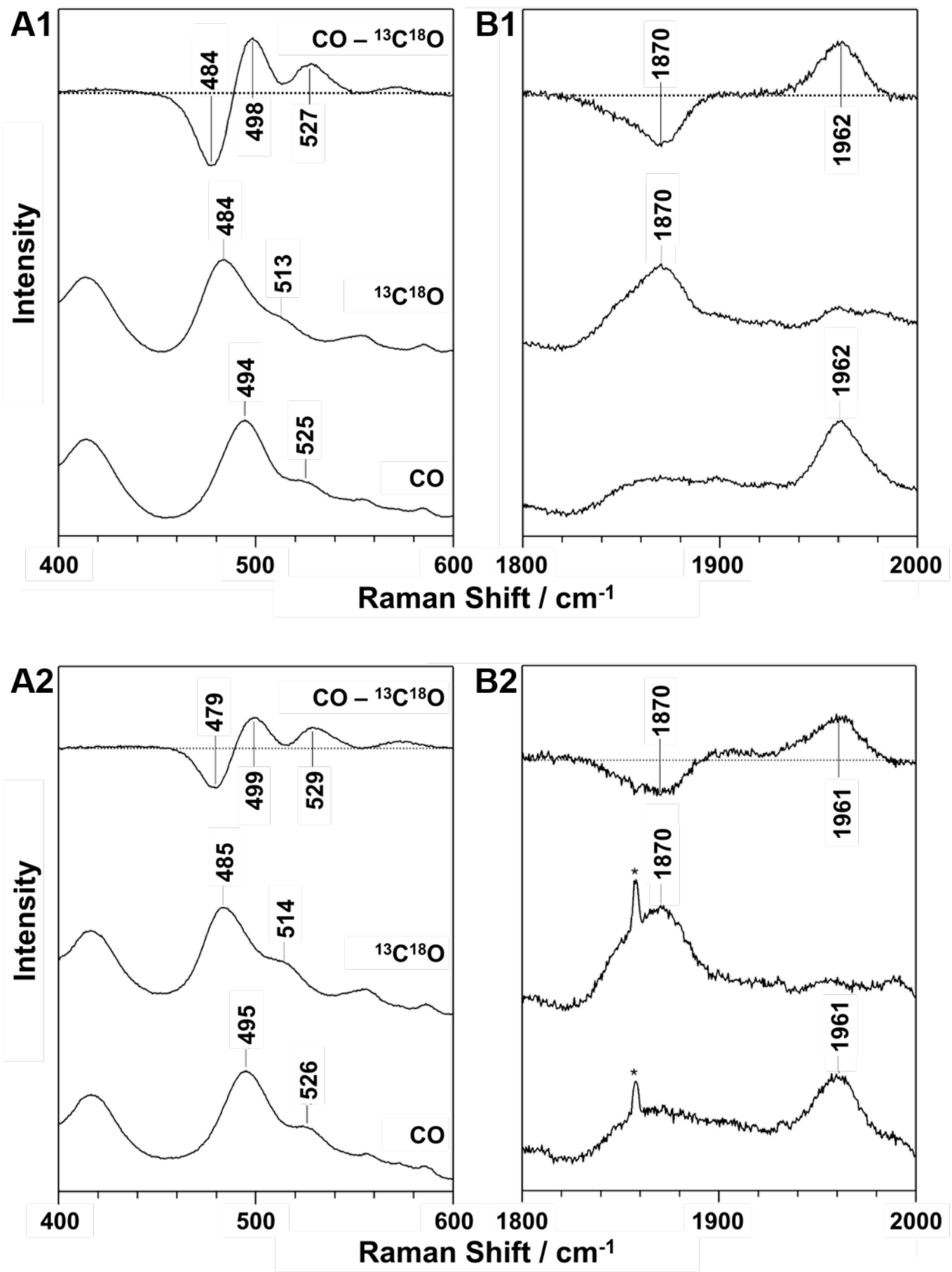

Fig. 5: Resonance Raman spectra of Fe(II)-CO complexes of IRPs. The low-frequency (A) and high-frequency (B) regions of the resonance Raman spectra for CO adducts of reduced heme-bound IRP1 (1) and IRP2 (2) excited at $413.1 \mathrm{~nm}$. Asterisks mark the positions of laser plasma lines. 


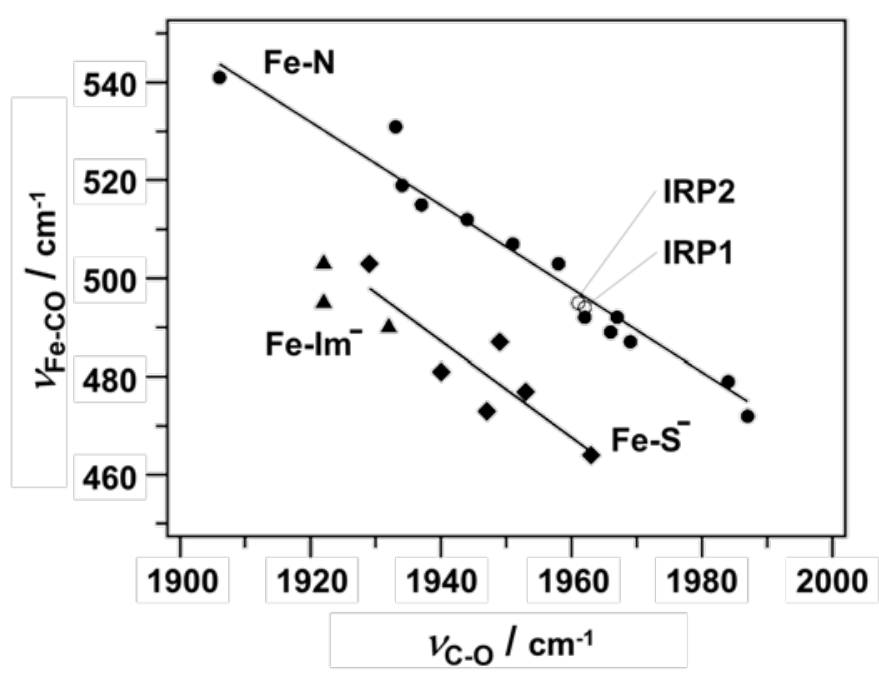

Fig. 6: Correlation plot between $\nu_{\text {Fe-Co }}$ and $\nu_{\text {FeC-O }}$ of hemoproteins and porphyrin model compounds. Proteins with an anionic ligand $(\bullet)$, proteins with a neutral ligand $(\bullet)$, and model complexes with an anionic ligands $(\boldsymbol{\Delta})$. Data for IRP1 and IRP2 are represented as 


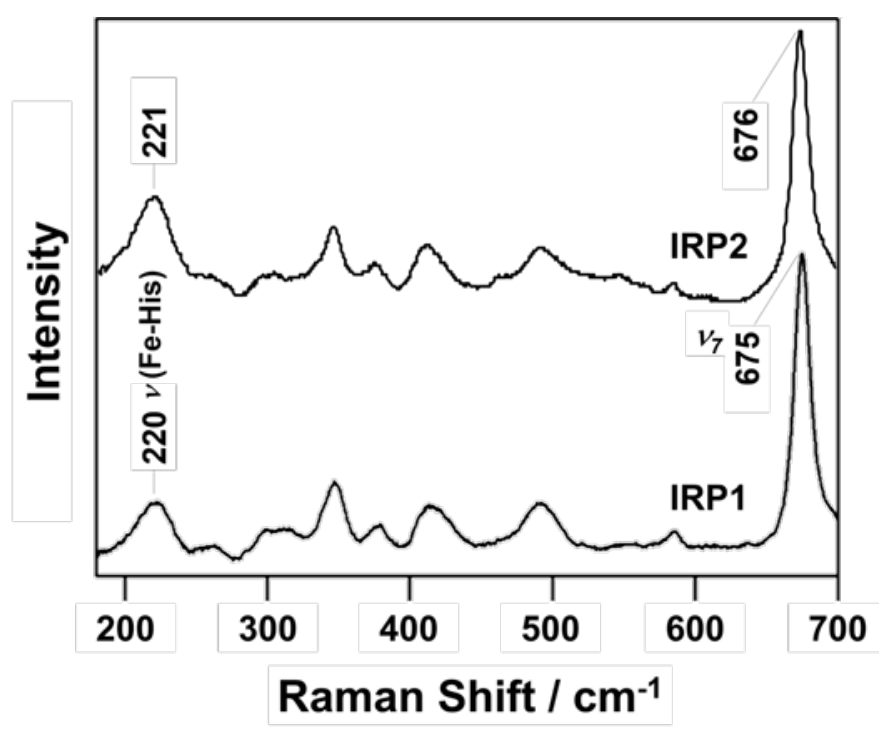

Fig. 7: Resonance Raman spectra of photodissociated products of CO adducts of IRPs in the low-frequency regions. Ferrous-CO complexes of IRP1 (A) and IRP2 (B). The protein concentration was approximately $30 \mu \mathrm{M}$ in $50 \mathrm{mM}$ Tris-HCl buffer, $\mathrm{pH}$ 7.4, in the presence of two molar equivalents of heme. Excitation wavelength was $441.6 \mathrm{~nm}$. 

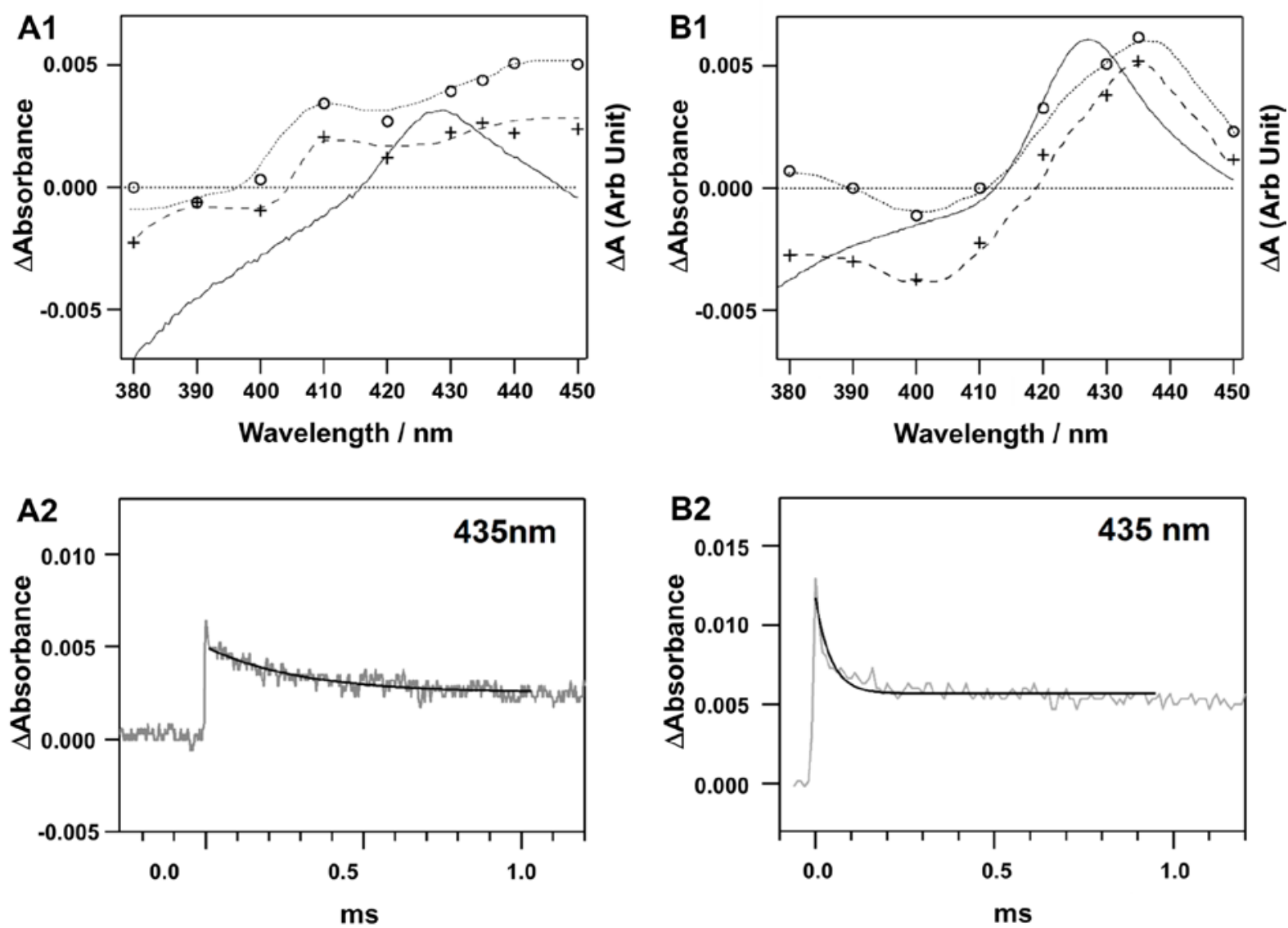

Figure 8

Fig. 8: Comparison of kinetic difference spectra and absorbance changes for IRPs after

pulse radiolysis. Spectra were measured at $100 \mu$ s (circle and dotted line) and 1.0 ms (plus and dashed line) after pulse radiolysis of IRP1 (A1), IRP2 (B1). The difference spectra between dithionite-reduced and oxidized IRPs are shown as solid lines. The left axis shows the change in absorbance $(\Delta \mathrm{A})$ for the kinetic difference spectra, and the right axis shows the change in absorbance for the static difference spectrum. Absorbance changes of IRP1 (A2) and IRP2 (B2) was monitored at $435 \mathrm{~nm}$. The fitting curves shown in the figures were obtained by the single-exponential fitting. 
HRM outside of IDD domain

(IRP1 and IRP2)

Ferric State

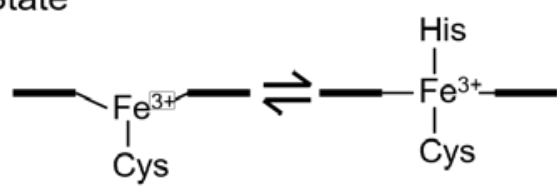
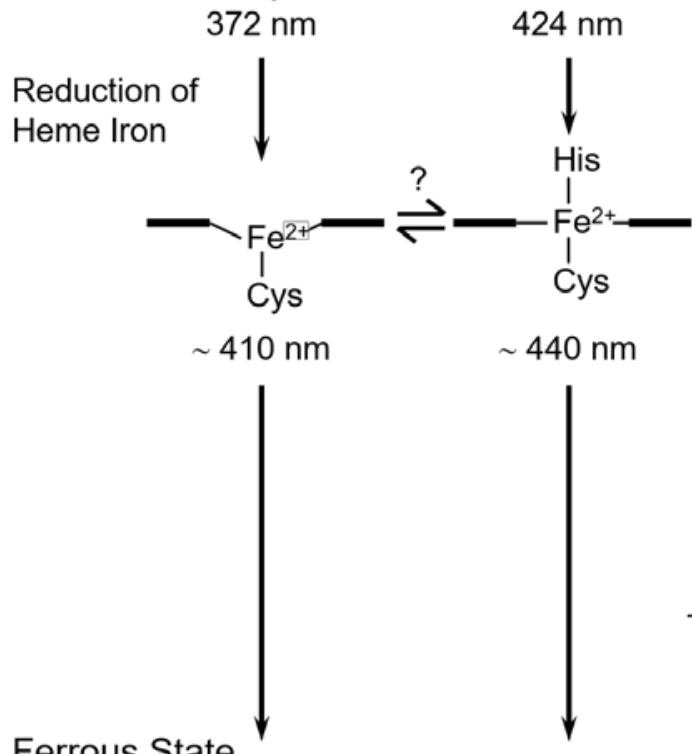

Ferrous State

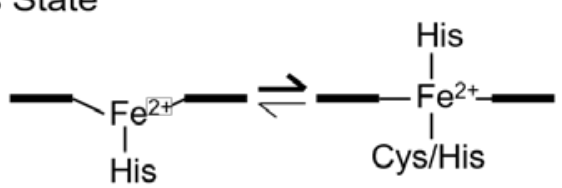
$425 \mathrm{~nm}$

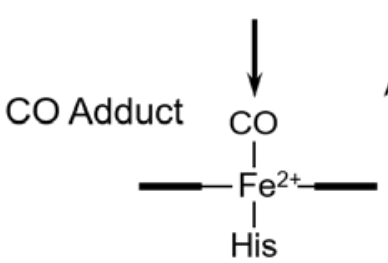

$421 \mathrm{~nm}$

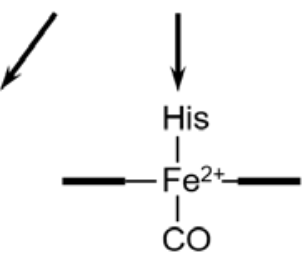

$421 \mathrm{~nm}$

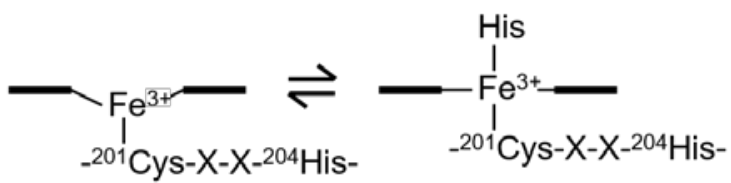

$373 \mathrm{~nm}$

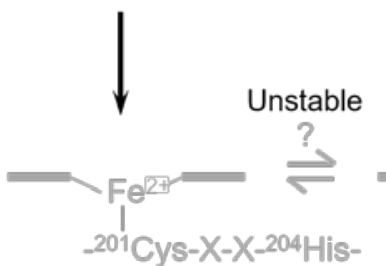

$425 \mathrm{~nm}$
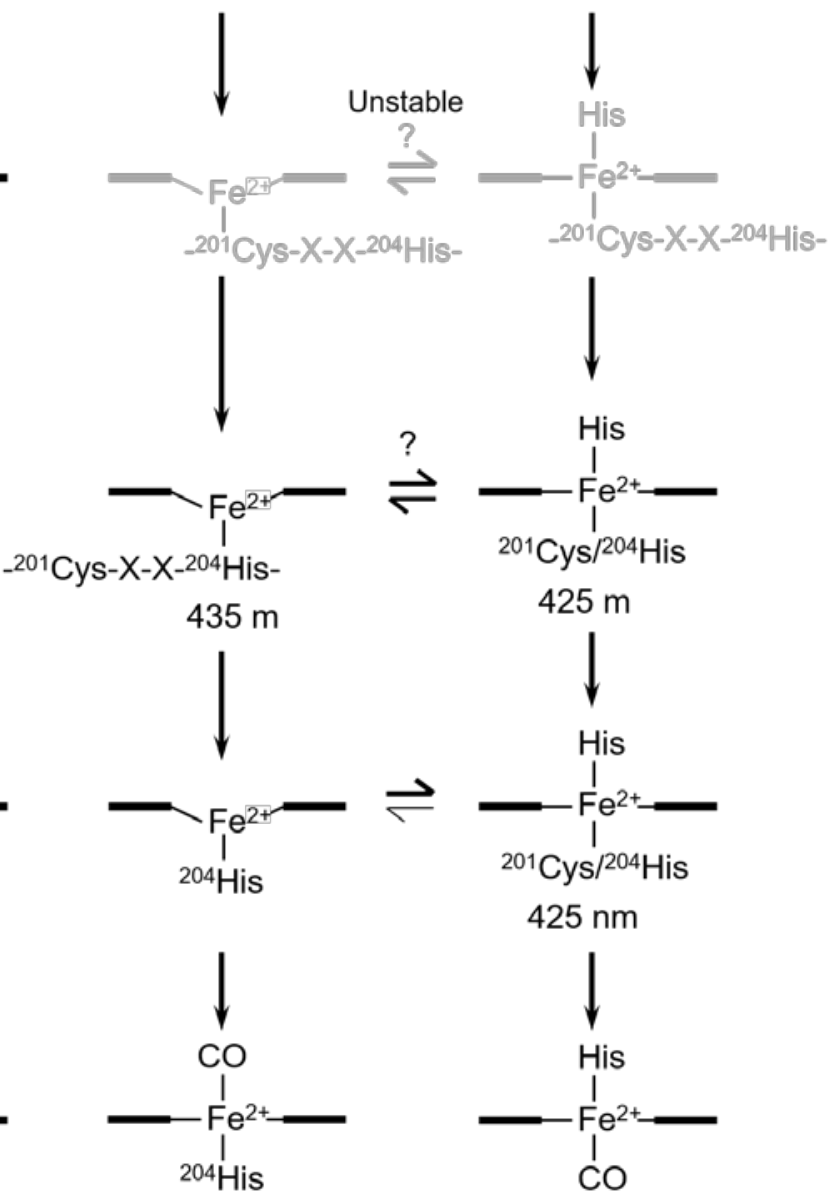

$421 \mathrm{~nm}$

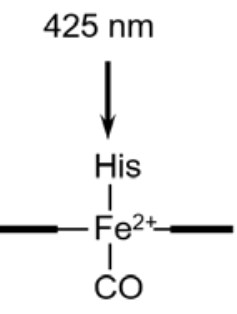

$421 \mathrm{~nm}$

Fig. 9: Model structures of heme coordination at the HRM region outside of (left) and in (right) the IDD domain.

The species not confirmed by spectroscopy are gray. The wavelengths of the peak in the Soret region are shown below. 
Table 1: Absorption peaks for hemoproteins.

\begin{tabular}{|c|c|c|c|c|}
\hline Proteins & Coordination & Soret & Visible & Reference \\
\hline \multicolumn{5}{|l|}{ Fe(III) complexes } \\
\hline IRP1 & Cys, Cys/His & $372,415^{\mathrm{a}}$ & broad & This work \\
\hline IRP2 & Cys, Cys/His & $373,415^{\mathrm{a}}$ & broad & This work \\
\hline Irr & Cys, His/His & 372,414 & broad & [39] \\
\hline HRI & Cys/? & 418 & 538 & {$[51]$} \\
\hline HRI-NTD & His/His & 415 & 533 & [56] \\
\hline CBS & His/Cys & 428 & 550 & [31] \\
\hline CooA & Cys/Pro & 424 & 541,566 & [57] \\
\hline P450cam & Cys & 391 & 511,646 & [58] \\
\hline P450cam(Imidazole) & Cys/Imidazole & 425 & 542,574 & [58] \\
\hline P420 & Cys & 422 & 541,566 & [35] \\
\hline Aquomet $\mathrm{Mb}$ & $\mathrm{His} / \mathrm{H}_{2} \mathrm{O}$ & 409 & 505,630 & [34] \\
\hline Cytochrome $b_{5}$ & His/His & 412 & $530-560^{\mathrm{b}}$ & [59] \\
\hline \multicolumn{5}{|l|}{$\mathrm{Fe}(\mathrm{II})$ complexes } \\
\hline IRP1 & His/(Cys or His) & 423 & 532, 559 & This work \\
\hline IRP2 & His/(Cys or His) & 425 & 530,559 & This work \\
\hline Irr & His, His/His & 423 & broad & {$[60]$} \\
\hline HRI & His/? & 426 & 531,560 & [51] \\
\hline HRI-NTD & His/His? & 428 & 530,560 & [56] \\
\hline CBS, pH 8.0 & His/Cys & 448 & 540,571 & [31] \\
\hline CBS, pH 6.0 & His/Cys & 425 & 530,558 & {$[31]$} \\
\hline CooA & His/Pro & 426 & 529, 559 & {$[57]$} \\
\hline P450cam & Cys & 408 & 543 & [33] \\
\hline P450cam(pyridine) & Cys/pyridine & 444 & 538,566 & [33] \\
\hline P420cam & Cys & 424 & 530,558 & {$[35]$} \\
\hline Deoxy Mb & His & 434 & 559 & {$[34]$} \\
\hline Cytochrome $b_{5}$ & His/His & 423 & 525,556 & [59] \\
\hline \multicolumn{5}{|l|}{$\mathrm{Fe}(\mathrm{II})-\mathrm{CO}$ complexes } \\
\hline IRP1 & His & 421 & 540,568 & This work \\
\hline IRP2 & His & 421 & 540,569 & This work \\
\hline HRI(CO) & His & 421 & 539, 565 & {$[51]$} \\
\hline HRI-N-terminal domain(CO) & His & 422 & 537,569 & {$[56]$} \\
\hline CBS(CO) & His & 420 & 540,570 & {$[31]$} \\
\hline CooA(CO) & His & 422 & 540,568 & {$[57]$} \\
\hline P450cam(CO) & Cys & 446 & 551 & [33] \\
\hline P420cam(CO) & His & 420 & 540,572 & {$[35]$} \\
\hline $\mathrm{MbCO}$ & His & 420 & 541,576 & {$[34]$} \\
\hline
\end{tabular}

${ }^{\mathrm{a}}$ Shoulder peak

${ }^{\mathrm{b}}$ Broad peak 
Table 2: Frequencies of spin state markers for hemoproteins.

\begin{tabular}{|c|c|c|c|c|c|c|}
\hline Proteins & Coordination & $\begin{array}{c}\text { Fe-axial } \\
\text { ligand }\end{array}$ & $v_{4}$ & $v_{3}$ & $v_{2}$ & Reference \\
\hline \multicolumn{7}{|l|}{ Fe(III) complexes } \\
\hline IRP1 & Cys, Cys/His & 331 & 1372 & 1489, 1500 & 1571 & This work \\
\hline IRP2 & Cys, Cys/His & 333 & 1372 & 1490, 1500 & 1583 & This work \\
\hline CBS & His/Cys & 312 & 1372 & 1500 & 1575 & [31] \\
\hline P450cam & Cys & 351 & 1368,1372 & 1488 & 1570,1582 & [61] \\
\hline P420cam & Cys & n.d. ${ }^{\mathrm{a}}$ & 1374 & 1491,1503 & 1572,1588 & [61] \\
\hline Aquomet Mb & His & n.d. & 1373 & 1503 & 1584 & [62] \\
\hline Cytochrome $b_{5}$ & His/His & n.d. & 1374 & 1506 & 1583 & [63] \\
\hline $\mathrm{Fe}^{3+}(\mathrm{PP}) \mathrm{Im}_{2}^{\mathrm{b}}$ & $\operatorname{Im} / \operatorname{Im}$ & n.d. & 1374 & 1503 & 1582 & [63] \\
\hline \multicolumn{7}{|l|}{ Fe(II) complexes } \\
\hline IRP1 & His/(Cys or His) & 220 & 1359 & 1469,1492 & 1580 & This work \\
\hline IRP2 & His/(Cys or His) & 221 & 1360 & 1470,1492 & 1582 & This work \\
\hline CBS, pH 8.0 & His/Cys & n.d. & 1358 & 1493 & 1585 & [31] \\
\hline P450cam & Cys & n.d. & 1345 & 1468 & 1563 & [61] \\
\hline P420cam & Cys & n.d. & 1361 & 1470,1493 & 1560,1583 & [61] \\
\hline Deoxy Mb & His & 220 & 1357 & 1473 & 1564 & {$[41,64]$} \\
\hline Cytochrome $b_{5}$ & His/His & n.d. & 1360 & 1492 & 1582 & [63] \\
\hline $\mathrm{Fe}^{2+}(\mathrm{PP}) \mathrm{Im}_{2}$ & $\operatorname{Im} / \operatorname{Im}$ & n.d. & 1360 & 1492 & 1582 & [63] \\
\hline Fe(II)-CO complexes & & $\mathrm{Fe}-\mathrm{CO}, \mathrm{FeC}-\mathrm{O}$ & & & & \\
\hline IRP1(CO) & His & 494,1962 & 1371 & 1497 & 1582 & This work \\
\hline IRP2(CO) & His & 495,1961 & 1373 & 1496 & 1583 & This work \\
\hline P450cam(CO) & Cys & 465 & 1371 & 1497 & 1588 & {$[61]$} \\
\hline P420cam(CO) & His & 496 & 1372 & 1498 & 1583 & {$[61]$} \\
\hline $\mathrm{MbCO}$ & His & 510,1944 & 1372 & 1500 & 1587 & {$[43,44]$} \\
\hline $\mathrm{Mb}\left({ }^{64} \mathrm{His} \rightarrow\right.$ Leu $)(\mathrm{CO})$ & His & 489,1966 & n.d. & n.d. & n.d. & {$[45,46]$} \\
\hline
\end{tabular}

${ }^{\mathrm{a}}$ Not determined, bis-imidazole-ligated porphyrin. 
Synopsis for the Graphical Abstract:

Both iron regulatory protein (IRP)-1 and 2 bind heme to the heme regulatory motif (HRM), but only IRP2 forms a 5-coordinate His-ligated heme immediately after the reduction. The formation of the 5-coordinate species probably due to the structural flexibility of IRP2 would differentiate function of heme in two IRPs. 